\title{
Hydrophilic 2,9-bis-triazolyl-1,10- phenanthroline ligands enable selective Am(iii) separation: a step further towards sustainable nuclear energy
}

Article

Accepted Version

Edwards, A. C., Mocilac, P., Geist, A., Harwood, L. M., Sharrad, C. A., Burton, N. A., Whitehead, R. C. and Denecke, M. A. (2017) Hydrophilic 2,9-bis-triazolyl-1, 10-phenanthroline ligands enable selective Am(iii) separation: a step further towards sustainable nuclear energy. Chemical Communications, 53 (36). pp. 5001-5004. ISSN 1364-548X doi: https://doi.org/10.1039/c7cc01855j Available at https://centaur.reading.ac.uk/70201/

It is advisable to refer to the publisher's version if you intend to cite from the work. See Guidance on citing.

To link to this article DOI: http://dx.doi.org/10.1039/c7cc01855j

Publisher: The Royal Society of Chemistry

All outputs in CentAUR are protected by Intellectual Property Rights law, including copyright law. Copyright and IPR is retained by the creators or other copyright holders. Terms and conditions for use of this material are defined in the End User Agreement. 


\section{www.reading.ac.uk/centaur}

\section{CentAUR}

Central Archive at the University of Reading

Reading's research outputs online 


\section{ChemComm}

\section{COMMUNICATION}

\section{Hydrophilic 2,9-bis-triazolyl-1,10-phenanthroline ligands enable selective Am(III) separation: a step further towards sustainable nuclear energy†}

Received 00th January 20xx Accepted 00th January 20xx

DOI: $10.1039 / \times 0 \times x 00000 x$
Alyn C. Edwards, ${ }^{\text {P Pavle Mocilac, }}{ }^{\text {a }}$ Andreas Geist, ${ }^{b}$ Laurence M. Harwood, ${ }^{c}$ Clint A. Sharrad, ${ }^{d}$ Neil A. Burton, ${ }^{\text {a }}$ Roger C. Whitehead ${ }^{a^{*}}$ and Melissa A. Denecke $\mathrm{e}^{*}$

www.rsc.org/

The first hydrophilic, 1,10-phenanthroline derived ligands consisting of only $\mathrm{C}, \mathrm{H}, \mathrm{O}$ and $\mathrm{N}$ atoms for the selective extraction of $\mathrm{Am}$ (III) from spent nuclear fuel are reported herein. One of these 2,9-bis-triazolyl-1,10-phenanthroline (BTrzPhen) ligands combined with a non-selective extracting agent, was found to exhibit process-suitable selectivity for $\mathrm{Am}$ (III) over $\mathrm{Eu}(\mathrm{III})$ and $\mathrm{Cm}$ (III), providing a clear step forward.

The ever-increasing demand for cost-effective, secure and environmentally benign energy, has led to a recently renewed global interest in nuclear power. ${ }^{1}$ In addition to the existing nuclear nations, there are now in excess of twenty emerging countries considering the prospects of nuclear energy programmes. $^{2}$ This projected growth means that the environmental impact and thus public perception of nuclear energy is becoming an increasing priority for the international nuclear community. ${ }^{3,4}$ Many nations are now developing innovative nuclear fuel cycles to separate the transuranic elements ( $\mathrm{Pu}, \mathrm{Np}, \mathrm{Am}$ and $\mathrm{Cm}$ ) from spent nuclear fuel in order to either use them in recycled fuel or transmute these relatively long-lived transuranic isotopes. These spent fuel management strategies aim to reduce the long-term radiotoxicity and heat generation of the spent fuel, to improve resource utilisation and facilitate the long term safety of a geological disposal facility (GDF).5,6 Within this approach, multiple advanced hydrometallurgical actinide(III)/ lanthanide(III) partitioning processes have been proposed for the treatment of advanced PUREX (Plutonium URanium EXtraction) raffinate, which consists of the transuranic

a. School of Chemistry, The University of Manchester, Oxford Road, Manchester, M13 9PL, UK. E-mail: roger.whitehead@manchester.ac.uk

b. Karlsruhe Institute of Technology (KIT), Institute for Nuclear Waste Disposal (INE), Karlsruhe, Germany. E-mail: andreas.geist@kit.edu

Department of Chemistry, The University of Reading, Whiteknights, Reading, RG6 6AD, UK. E-mail: I.m.harwood@reading.ac.uk

d. School of Chemical Engineering, The University of Manchester, Oxford Road, Manchester, M13 9PL, UK. E-mail: clint.sharrad@manchester.ac.uk

e. Dalton Nuclear Institute, The University of Manchester, Oxford Road, Manchester, M13 9PL, UK. Email: melissa.denecke@manchester.ac.uk

+ Electronic Supplementary Information (ESI) available: Full synthetic details, key NMR spectra, solvent extraction procedures and additional data, TRLFS setup and procedures and X-ray crystallographic data.. See DOI: 10.1039/x0xx00000x elements and fission products including the lanthanides (Ln). ${ }^{1,7}$ This partitioning is a pre-target fabrication necessity due to the high neutron capture cross section of the Ln. ${ }^{8}$ Within Europe, the recently developed SANEX (Selective ActiNide EXtraction) process has allowed this challenging $A n(I I I) / \operatorname{Ln}(I I I)$ separation to be readily accomplished using lipophilic, soft $N$-type donor BTP (bis-triazinyl-pyridine) ${ }^{9}$, BTBP (bis-triazinyl-bipyridine) ${ }^{10}$ or BTPhen (bis-triazinyl-1,10-phenanthroline) ${ }^{11-13}$ ligand systems to selectively remove the trivalent actinides (An) from DIAMEX (DIAMide EXtraction) extract. The DIAMEX process removes both $A n(I I I)$ and $\operatorname{Ln}($ III) from the non-Ln fission products using a non-selective diglycolamide in advanced PUREX raffinate and is an essential prerequisite to a SANEX type process. ${ }^{14}$

More recently, the $i$-SANEX (innovative-SANEX) ${ }^{15}$ process has emerged as a promising alternative for $\mathrm{An}(\mathrm{III}) / \mathrm{Ln}(\mathrm{III})$ separations. This advanced multi-step, partitioning process uses the diglycolamide $N, N, N^{\prime}, N^{\prime}$-tetraoctyl-diglycolamide TODGA, Fig. S1 to co-extract both $\mathrm{An}$ (III) and $\operatorname{Ln}$ (III) into an organic phase followed by selective An(III) back-extraction using a hydrophilic complexant, removing the need to implement individual DIAMEX and SANEX type processes. The most promising hydrophilic complexants for implementation in $i$-SANEX, studied thus far, are sulfonated versions of the BTP, BTBP and BTPhen ligands explored for use in SANEX (e.g. $\mathrm{SO}_{3}-$ Ph-BTBP/BTPhen; Fig. S1). An additional spent fuel management strategy being considered post An(III) separation from $\operatorname{Ln}(\mathrm{III})$ is the partitioning of $\mathrm{Am}$ (III) from $\mathrm{Cm}$ (III). One such process being explored is AmSel (Americium Selective Extraction). ${ }^{16}$ Accomplishing this extremely challenging separation is most advantageous as curium isotopes are shortlived (e.g. ${ }^{244} \mathrm{Cm}, t_{1 / 2}=18$ years), intensely radioactive and strong neutron emitters, making $\mathrm{Cm}$ (III) based fuel fabrication unfeasible. ${ }^{17}$ In contrast, Am based fuels can be feasibly produced for fast reactor systems. The AmSel process separates $A m$ (III) from $\mathrm{Cm}$ (III) and $\mathrm{Ln}$ (III) by stripping only Am(III) from a TODGA solvent containing Am(III), $\mathrm{Cm}$ (III) and Ln(III). A subtle selectivity of TODGA for Cm(III) over Am(III) $\left(\mathrm{SF}_{\mathrm{Cm}(\mathrm{III}) / \mathrm{Am}(\mathrm{III})} \approx 1.6\right)$ in conjunction with the similar subtle selectivity for $\mathrm{Am}$ (III) over $\mathrm{Cm}$ (III) by hydrophilic $\mathrm{SO}_{3}-\mathrm{Ph}$ BTBP/BTPhen $\left(\mathrm{SF}_{\mathrm{Am}(\mathrm{III}) / \mathrm{Cm}(\mathrm{III})} \approx 1.6\right)$ is exploited ${ }^{16,18,19}$ 

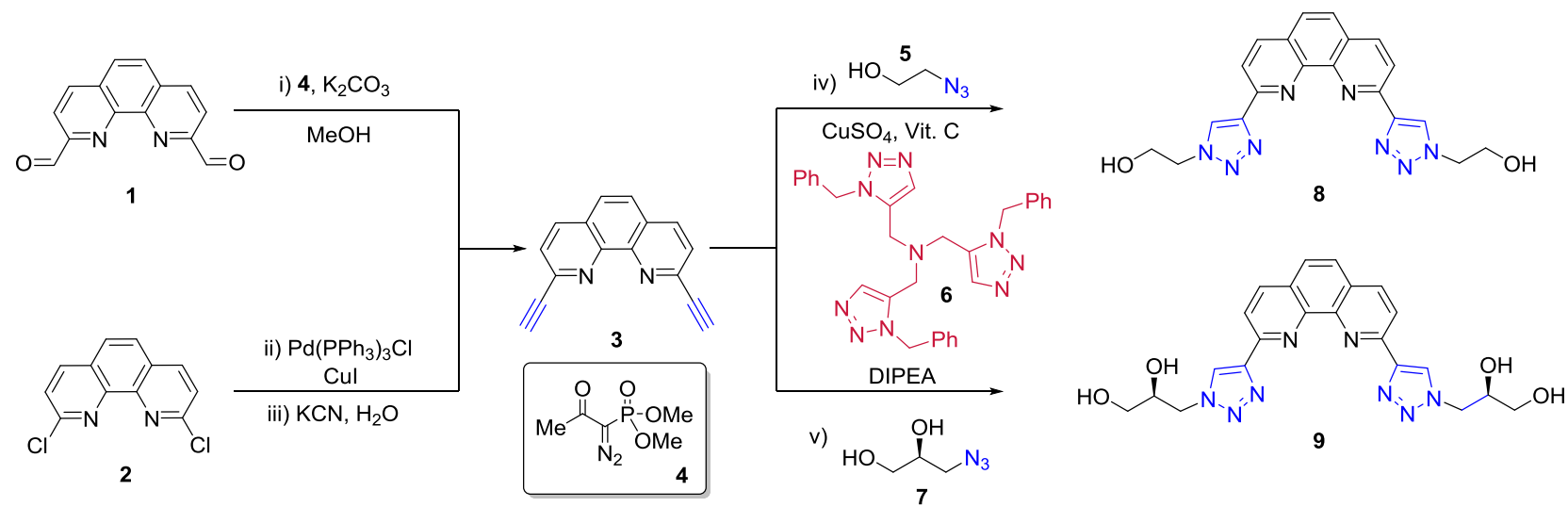

Scheme 1 Synthesis of hydrophilic, 2,9-bis-(1,2,3)-triazolyl-1,10-phenanthroline (BTrzPhen) ligands 8 and 9

Despite their many advantages, the $i$-SANEX and AmSel processes currently propose the use of sulfur containing extractants, which are unsuitable for incineration and as a result generate additional radioactive waste-streams. Consequently, a series of hydrophilic, pyridine-2,6-bis $(1 \mathrm{H}$ 1,2,3-triazol-4-yl) (PyTri) ligands (Fig. S1) was evaluated by Casnati et al. In synergy with TODGA, these PyTri ligands were reported to be highly $\mathrm{An}(\mathrm{III})$ selective $\left(\mathrm{SF}_{\mathrm{Eu}(\mathrm{III}) / \mathrm{Am}(\mathrm{III})} \approx 100\right)$ however, no useful $\mathrm{Am}(\mathrm{III}) / \mathrm{Cm}$ (III) selectivity was observed. 20

With this in mind, we have developed a $\mathrm{C}, \mathrm{H}, \mathrm{O}, \mathrm{N}$ compliant extractant, suitable for use the in $i$-SANEX and/or AmSel processes thus allowing for the efficient partitioning and reuse of Am(III) in spent nuclear fuel. During this process, we sought to combine the superior chelating properties of the 1,10phenanthroline scaffold with the hydrophilicity of hydroxylated-1,2,3-triazolyl moieties. The resulting 2,9-bis(1H-1,2,3-triazol-4-yl)-1,10-phenan-throline (BTrzPhen) ligands (8-9) are shown in Scheme.1. During the synthesis of ligands 8 and 9, two alternative synthetic routes to the 2,9-diethynyl1,10-phenanthroline intermediate (3) were explored (Scheme 1). The first of these routes employed a Seyferth-Gilbert homologation of commercially available 1,10-phenanthroline2,9-dicarb-aldehyde (1) using the Bestmann-Ohira reagent (4). Following column chromatography, this protocol provided intermediate 3 in a modest, $49 \%$ yield. The second protocol entailed a Sonogashira coupling of commercial 2,9-dichloro1,10-phenanthroline (2) and ( $t$-butyldimethyl-silyl)acetylene, followed by subsequent deprotection. Over the two steps, $\mathbf{3}$ was obtained in $\mathbf{5 0} \%$ yield. Azides $\mathbf{5}$ and $\mathbf{7}$ were synthesised as previously described. ${ }^{20}$ Finally, the click reaction of bis-alkyne 3 with azides $\mathbf{5}$ and $\mathbf{7}$ was carried out in the presence of a preprepared, copper(II) tris[(1-benzyl-1H-1,2,3-triazol-4-yl)methyl] amine (TBTA, 6) complex, to inhibit competing copper(II) complexation with 1,10-phenanthroline. ${ }^{21}$ The target BTrzPhen ligands 8 and 9 were obtained in yields of $89 \%$ and $64 \%$ respectively. Both ligands 8 and $\mathbf{9}$ were found to be sufficiently soluble in aqueous $0.3-3.0 \mathrm{M} \mathrm{HNO}_{3}\left(\approx 10 \mathrm{mmol} \mathrm{L}^{-1}\right)$. The tetraol (9) was also found to be readily soluble at $\mathrm{HNO}_{3}$ concentrations $<0.3 \mathrm{M}$ (down to $0.01 \mathrm{M}$ ). The solubility of 8 and 9 in aqueous $\mathrm{HNO}_{3}$ solutions is a required property, as it is anticipated that advanced liquid-liquid extraction processes will be directly implemented on advanced PUREX raffinate $\left(\left[\mathrm{HNO}_{3}\right](\leq 4 \mathrm{M})\right.$. The ability of ligands 8 and 9 to back-extract the trivalent actinides selectively from a TODGA containing organic phase (5 vol\% 1-octanol in kerosene) was assessed using a series of ${ }^{241} \mathrm{Am}$ (III) and ${ }^{152} \mathrm{Eu}$ (III) spiked extraction experiments. To ensure that equilibrium was attained, the biphasic mixtures were shaken for $12 \mathrm{~h}$ on a benchtop shaker
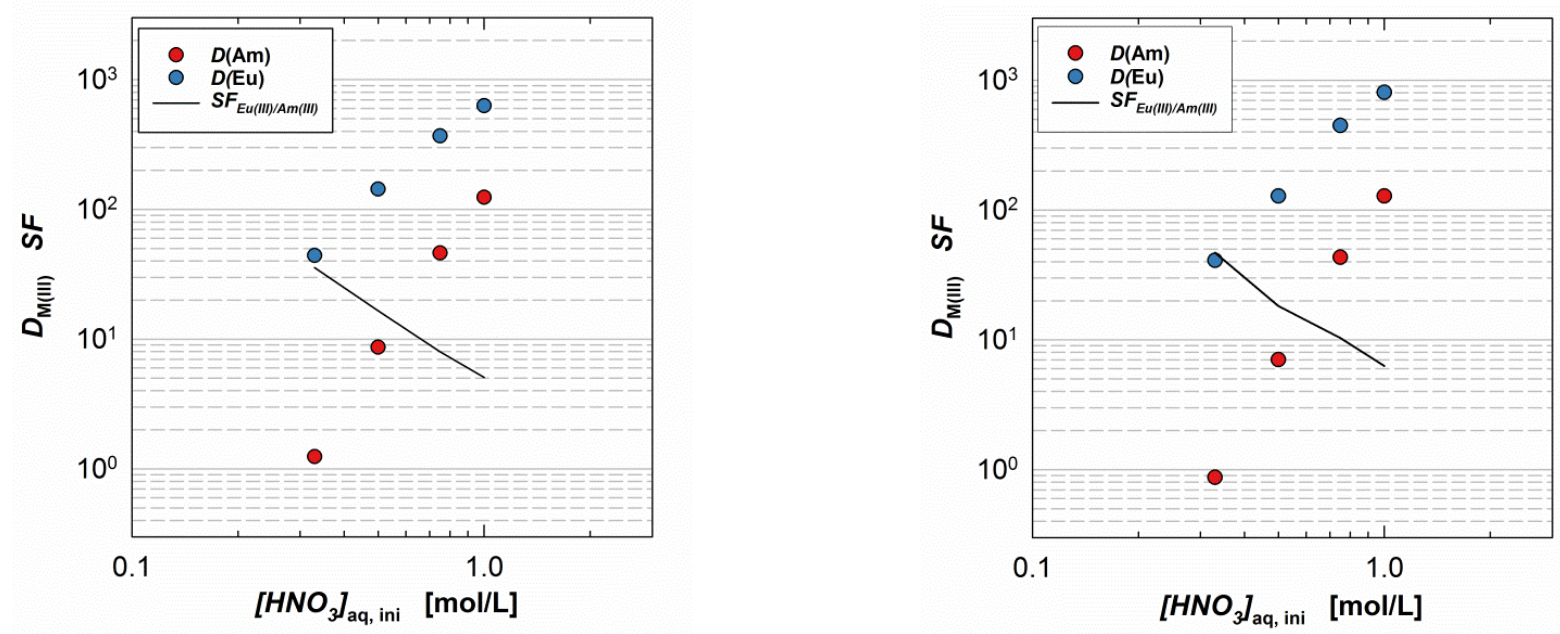

Fig. 1 Distribution ratios $\left(\mathrm{D}_{\mathrm{M}(\mathrm{III})}\right)$ and separation factors $\left(\mathrm{SF}_{\mathrm{Eu} / \mathrm{Am}}\right)$ obtained in the extraction of ${ }^{241} \mathrm{Am}(\mathrm{III})$ and ${ }^{152} \mathrm{Eu}(\mathrm{III})$ by 8 (left) and 9 (right). Organic phase: TODGA (0.2 mol $\left.\mathrm{L}^{-1}\right)$ and 5 vol\% 1-octanol in kerosene. Aqueous phase: $\mathrm{HNO}_{3}\left(0.33-1.0 \mathrm{~mol} \mathrm{~L}^{-1}\right)^{\ddagger}$ and BTrzPhen ligands 8 and $9\left(10 \mathrm{mmol} \mathrm{L}{ }^{-1}\right)$. Vortex Shaker $(40 \mathrm{~Hz})$ for $12 \mathrm{hours}$ at $20^{\circ} \mathrm{C} \pm 0.5{ }^{\circ} \mathrm{C}$. 
and the subsequent distribution ratios $\left(D_{M(I I I)}\right)$ recorded using $\gamma$-spectroscopy. The resulting equilibrium extraction data as a function of $\mathrm{HNO}_{3}$ concentration are presented in Fig.1.

As anticipated, 8 and $\mathbf{9}$ exhibit similar extraction behaviour to one another, with both signifying a clear selectivity for Am(III) over $\mathrm{Eu}$ (III) from a TODGA containing organic phase. Gratifyingly, ligand 9 was found to exhibit process suitable $D_{c}$ values at $0.33 \mathrm{M} \mathrm{HNO}_{3}$ with $D_{A m}<1$ and $D_{E u}>10$. Separation factors $\left(\mathrm{SF}_{\mathrm{Eu} / \mathrm{Am}}\right)$ of 36 and 47 were obtained for 8 and 9 in 0.33 $\mathrm{M} \mathrm{HNO}_{3}$ respectively, and decrease as a function of increasing $\left[\mathrm{HNO}_{3}\right]$. This observed loss in separation performance with increasing $\left[\mathrm{HNO}_{3}\right]$ is also observed for hydrophilic BTP ${ }^{15}$, BTBP $^{16}$, BTPhen ${ }^{18}$ and PyTri ${ }^{20}$ ligands and is attributed to the increased degree of ligand protonation and thus decreased free ligand concentration.

Despite the $\mathrm{SF}_{\mathrm{Eu} / \mathrm{Am}}$ for ligands 8 and $\mathbf{9}$ being approximately half of those reported for the PyTri series $\left(\mathrm{SF}_{\mathrm{Eu} / \mathrm{Am}} \approx 100\right)$, it is worth noting that extraction with these latter complexants requires exceptionally high ligand concentrations $\left(80 \mathrm{mmol} \mathrm{L}^{-1}\right.$ c.f. $10 \mathrm{mmol} \mathrm{L}^{-1}$ (BTrzPhen) due to their limited affinity $\left(\mathrm{EuCl}_{3}\right.$ $\left.\log \beta_{1: 1}=2.4-3.0\right)$. The selectivity of 9 for $A m(I I I)$ over $C m$ (III) from a TODGA containing organic phase was then assessed using a second series of extraction experiments spiked with ${ }^{244} \mathrm{Cm}$. The equilibrium distribution ratios at $0.3 \mathrm{M} \mathrm{HNO}_{3}$ were determined as $\mathrm{D}_{\mathrm{Cm} \text { (III) }} \approx 5$ and $\mathrm{D}_{\mathrm{Am} \text { (III) }} \approx 2$ by $\alpha$-spectroscopy, leading to a $\mathrm{SF}_{\mathrm{Cm} / \mathrm{Am}}$ of 2.5. This separation factor is identical to that reported for the $\mathrm{SO}_{3}$-BTBP/BTPhen and TODGA containing systems. ${ }^{16}$ Despite providing no improvement in $\mathrm{Am}$ vs $\mathrm{Cm}$ selectivity, this is the first $\mathrm{C}, \mathrm{H}, \mathrm{O}, \mathrm{N}$ compliant, 1,10phenanthroline derived donor ligand to achieve this $\mathrm{Am} / \mathrm{Cm}$ separation. In order to probe the complexation behaviour of the BTrzPhen ligands further, a Eu(III) complex of ligand $\mathbf{8}$ was synthesised using $\mathrm{Eu}(\mathrm{III})$ triflate. Growth of single crystals suitable for XRD analysis was accomplished by the slow evaporation of a saturated $\mathrm{CH}_{3} \mathrm{CN}$ solution. The innercoordination sphere of the resulting (1:2, [M:L]) 9-coordinate Eu(III)complex comprises two BTrzPhen molecules (8) and a molecule of water (Fig.2). Three non-coordinating triflate anions for charge neutrality are located in the asymmetric unit, with structure refinement revealing one anion to be highly disordered. Since our focus surrounds the structure of the $\left[\mathrm{Eu}(8)_{2} \mathrm{H}_{2} \mathrm{O}\right]^{3+}$ complex cation and not the intermolecular bonding within the crystal structure, it was deemed appropriate to make use of the SQUEEZE procedure embedded

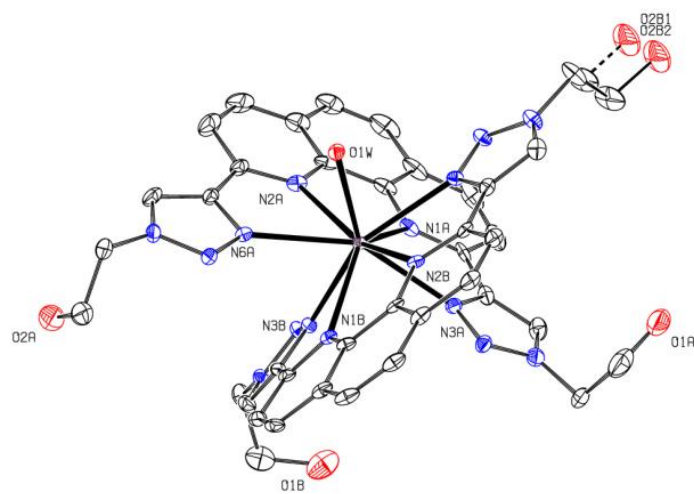

Fig 2. Single crystal X-ray diffraction structure of the $\left[\mathrm{Eu}(\mathbf{8})_{2} \mathrm{OTf} f_{3}\right]$ complex.

\begin{tabular}{|c|c|c|c|}
\hline Distances / $\AA$ & $\begin{array}{c}\text { Eu-N } \\
\text { (phen/bypy) }\end{array}$ & $\begin{array}{c}\text { Eu-N } \\
\text { (triazine/ole) }\end{array}$ & $\begin{array}{c}\mathrm{Eu}-\mathrm{O} \\
\left(\mathrm{H}_{2} \mathrm{O} / \mathrm{NO}_{3} / \mathrm{OTf}\right)\end{array}$ \\
\hline$\left[\mathrm{Eu}(\mathrm{BTrz} \operatorname{Phen}(\mathbf{8}))_{2} \mathrm{H}_{2} \mathrm{O}\right]$ & 2.540 & 2.547 & 2.4183 \\
\hline$\left[\mathrm{Eu}\left(\mathrm{CyMe}_{4}-\mathrm{BTPhen}\right)_{2} \mathrm{H}_{2} \mathrm{O}\right]^{22}$ & 2.515 & 2.540 & 2.414 \\
\hline$\left[\mathrm{Eu}\left(\mathrm{CyMe}_{4}-\mathrm{BTBP}\right)_{2} \mathrm{NO}_{3}\right]^{22}$ & 2.566 & 2.572 & 2.564 \\
\hline$\left[\mathrm{Eu}(\mathrm{CyMe} 4-\mathrm{BTBP})_{2} \mathrm{NO}_{3}\right]^{23}$ & 2.578 & 2.572 & 2.560 \\
\hline$\left[\mathrm{Eu}(\mathrm{CyMe} 4-\mathrm{BTBP})_{2} \mathrm{NO}_{3}\right]^{24}$ & 2.563 & 2.588 & 2.563 \\
\hline$\left[\mathrm{Eu}\left(\mathrm{CyMe}{ }_{4}-\mathrm{BTPhen}\right)_{2} \mathrm{NO}_{3}\right]^{11}$ & 2.582 & 2.587 & 2.567 \\
\hline $\begin{array}{l}\text { [Eu(bispyridinyl- } \\
\left.\text { Phen) }{ }_{2} \mathrm{H}_{2} \mathrm{O}\right], \mathrm{Z}^{\prime}=2^{25}\end{array}$ & 2.541 & 2.615 & 2.431 \\
\hline $\begin{array}{l}\text { [Eu(ethylene- } \\
\left.\text { BisPhen) }{ }_{2} \mathrm{OTf}\right]^{25}\end{array}$ & 2.576 & 2.576 & 2.392 \\
\hline $\begin{array}{l}\text { [Eu(bis-tetrazolyl- } \\
\left.\text { bipyridine }{ }_{2} \mathrm{H}_{2} \mathrm{O}\right]^{26}\end{array}$ & 2.565 & 2.528 & 2.442 \\
\hline
\end{tabular}

Table 1: Average bond distances in the first coordination sphere between the $\mathrm{Eu}(\mathrm{III})$ ion and heterocyclic $\mathrm{N}$-donor ligands and $\mathrm{O}$ atoms (coordinated water, nitrate or triflate) in the complex compounds indicated. Complex charge omitted.

in PLATON ${ }^{27}$ to eliminate this disordered counter-ion and thus allow refinement to converge to $\mathrm{R}=5.75 \%$. Metrical coordination parameters obtained, Eu-N, Eu-O bond lengths, $\mathrm{N}-\mathrm{Eu}-\mathrm{N}$ angles, inter-ligand angle and the $\mathrm{Eu}(\mathrm{III})$ 'shift', defined as the distance of Eu(III) from the intersection of the two ligand mean planes, are provided in the ESI, Table S2. Nearest neighbour bond lengths are presented in Table 1. For comparative purposes, coordination parameters for similar [1:2] complexes of Eu(III) with tetradentate, $\mathrm{N}$-donor ligands based on phenanthroline or bipyridine (containing flanking triazine, pyridine or tetrazolyl moieties) and water, nitrate or triflate molecule are also included.

This comparison reveals that the $\left[\mathrm{Eu}(\mathbf{8})_{2} \mathrm{H}_{2} \mathrm{O}\right]^{\prime \prime \prime}$ complex has the similar bond distances as analogous, $\mathrm{N}$-donor ligand complexes. There are some subtle differences in the average $\mathrm{Eu}-\mathrm{N}_{\text {triazine/triazole }}$ and $\mathrm{Eu}-\mathrm{N}_{\text {phen/bipy }}$ bond lengths, with the $\left[\mathrm{Eu}(8)_{2} \mathrm{H}_{2} \mathrm{O}\right]^{\prime \prime \prime}$ complex found to have marginally longer $\mathrm{M}-\mathrm{L}$ bonds than the analogous [ $\mathrm{Eu}\left(\mathrm{CyMe}_{4}-\mathrm{BTPhen}\right)_{2} \mathrm{H}_{2} \mathrm{O}$ ] complex, suggesting slightly weaker bonding. ${ }^{22}$ Further analysis of the data in Table 1 highlights that complexes containing an innercoordination sphere $\mathrm{NO}_{3}{ }^{-}$anion, typically have longer average $M-L$ bond lengths than those containing water. This is in excellent agreement with the recent report of EXAFS data by Dai et al. on $\mathrm{Me}_{2}$-BTPhen. ${ }^{28}$

The stability constants for the formation of the Eu(III) complexes of $\mathbf{8}$ and $\mathbf{9}$ were determined using a series of UV-vis titrations in organic $\left(\mathrm{CH}_{3} \mathrm{CN}: \mathrm{CH}_{3} \mathrm{Cl} 1: 1\right)$ and aqueous $\left(\mathrm{HNO}_{3}\right)$ media. The resulting spectroscopic data were processed and analysed by HyperQuad ${ }^{29}$, providing the apparent $\log \beta_{1: 1}$ and $\log \beta_{1: 2}$ values (Table 1). Titration of ligand 8 with $\mathrm{Eu}(\mathrm{III})$ in organic media, provided both $\log \beta_{1: 1}$ and $\log \beta_{1: 2}$ values; conversely, titration of 8 in $0.1 \mathrm{M} \mathrm{HNO}_{3}$ (see ESIt section 2.3) revealed exclusive formation of a 1:1 complex. Unfortunately, the insolubility of BTrzPhen 8 prevented titrations in $0.01 \mathrm{M}$ $\mathrm{HNO}_{3}$. The titration of ligand 9 in $0.01 \mathrm{M} \mathrm{HNO}_{3}$ provided both $\log \beta_{1: 1}$ and $\log \beta_{1: 2}$ values. The 1:2 stepwise stability constant is larger than that of the $1: 1$ complex so that the $1: 2$ complex of 


\begin{tabular}{ccccccc}
\hline Ligand & $\mathrm{Eu}(\mathrm{III})$ Salt & Solvent & $\log \beta_{1: 1}$ & $\mathrm{SD}^{\mathrm{a}}$ & $\log \beta_{1: 2}$ & $\mathrm{SD}^{\mathrm{a}}$ \\
\hline $\mathbf{8}$ & $\mathrm{Eu}(\mathrm{OTf})_{3}$ & $\mathrm{MeCN} / \mathrm{CHCl}_{3}$ & $\mathbf{8 . 1}$ & 0.150 & $\mathbf{1 4 . 7}$ & 0.270 \\
$\mathbf{8}$ & $\mathrm{Eu}\left(\mathrm{NO}_{3}\right)_{3}$ & $0.1 \mathrm{HNO}_{3}$ & 6.1 & 0.008 & $\mathrm{n} / \mathrm{a}^{\mathrm{b}}$ & $\mathrm{n} / \mathrm{a}^{\mathrm{b}}$ \\
$\mathbf{9}$ & $\mathrm{Eu}\left(\mathrm{NO}_{3}\right)_{3}$ & $0.01 \mathrm{HNO}_{3}$ & $\mathbf{6 . 6}$ & 0.050 & $\mathbf{1 3 . 5}$ & 0.060
\end{tabular}

Table 2: Metal-Ligand Stability Constants Determined Least Square Fits to UV-Visible Spectroscopic Titration Data Using Hypspec ${ }^{29}$ ( $T=25^{\circ} \mathrm{C}$ ) a Standard deviations determined by the fitting process, ${ }^{b}$ Unobtainable.

$\mathrm{Eu}(\mathrm{III})$ and ligand 9 dominates speciation in $0.01 \mathrm{M} \mathrm{HNO}_{3}$ (c.f speciation diagram, ESIt section 2.4); only a large excess of Eu(III) drives dissociation of the 1:2 species to the 1:1 complex. Generally, ligands 8 and $\mathbf{9}$ show good ability to coordinate $\mathrm{Eu}(\mathrm{III})$ although stability constants for $\mathbf{8}$ in organic media are smaller than those of $\mathrm{CyMe}_{4}-\mathrm{BTPhen}^{30}$. Future studies will encompass the determination of stability constants of $\mathbf{8}$ and $\mathbf{9}$ with Am(III) or Cm(III).

The luminescence properties of the Eu(III) triflate complex of ligand $\mathbf{8}$ were also investigated by fluorescence spectroscopy (see ESIt section 2.5). The most intense peak in the emission spectrum at $617 \mathrm{~nm}$ is the ${ }^{5} \mathrm{D}_{0} \rightarrow^{7} \mathrm{~F}_{2}$ "hypersensitive transition". Rather than direct excitation to the $4 \mathrm{f}$ states, the organic ligands are chromophores, absorbing light which is efficiently transferred via intramolecular energy transfer to $4 \mathrm{f}$ resonance levels of the $E u(I I I)$ ion; from there to the emitting excited ${ }^{5} D_{0}$, leading to enhanced luminescence. The very efficient ligandto-metal energy transfer is reflected in the absorption spectra being a near superposition of the excitation spectra measured at the $616 \mathrm{~nm}$ metal centred emission (ESI, Fig. S15). ${ }^{31}$ The lifetime of this $\mathrm{Eu}(\mathrm{III})$ complex $\left(\lambda_{\max }=617 \mathrm{~nm}\right)$ was found to be $1.8 \mathrm{~ms}\left(\sigma=1.56 \mu \mathrm{s}, \chi^{2}=1.209\right)$, which is similar to the lifetimes reported for Eu-BTPhen/BTBP complexes. ${ }^{22}$

In summary, we have two new, hydrophilic, 2,9-bis-triazolyl1,10-phenanthroline (BTrzPhen) ligands which show considerable promise for the recycling and management of minor actinides from spent nuclear fuel. We disclose the synthesis, $\mathrm{Eu}(\mathrm{III})$ speciation and liquid-liquid extraction properties of this exciting new ligand family. The BTrzPhen ligand 9 was found to exhibit process-suitable Am(III): Eu(III) and $\mathrm{Cm}$ (III):Am(III) separation factors from TODGA (at only 10 mmol $\mathrm{L}^{-1}$ ) containing organic phases. These promising, preliminary extraction results make ligand 9, the first $\mathrm{C}, \mathrm{H}, \mathrm{O}, \mathrm{N}$, compliant, 1,10-phenanthroline derived ligand to display suitable properties for the selective removal of Am(III) from $\mathrm{Ln}$ (III) and $\mathrm{Cm}(\mathrm{III})$. Further process development will be implemented in order to examine the impact of; additional Ln(III) ions, fission products (FP) and radiolysis on this promising extraction behaviour.

The authors thank the EPSRC for funding a Nuclear Fission Research, Science and Technology DTC (Nuclear FiRST) studentship EP/G037140/1 (A.C.E).

\section{Notes and references}

$\neq \mathrm{D}_{\mathrm{M}(\mathrm{III})}$ values at $3 \mathrm{M}\left[\mathrm{HNO}_{3}\right]$ were too large to be accurately determined $(>>1000)$.

1 K. L. Nash and M. Nilsson, Reprocessing and Recycling of Spent Nuclear Fuel, Elsevier, 2015.

2 International Energy Agency (IAEA), World Energy Outlook, 2016.
3 OECD-NEA, Public Attitudes to Nuclear Power, 2010.

4 W. Poortinga, M. Aoyagi and N. F. Pidgeon, Energy Policy, 2013, 62, 1204-1211.

5 C. Poinssot, S. Bourg, N. Ouvrier, N. Combernoux, C. Rostaing, M. Vargas-Gonzalez and J. Bruno, Energy, 2014, 69, 199-211.

6 OECD-NEA, Actinide and Fission Product Partitioning and Transmutation, 2007.

7 R. S. Herbst, P. Baron and M. Nilsson, Advanced Separation Techniques for Nuclear Fuel Reprocessing and Radioactive Waste Treatment, Elsevier, Cambridge, 2011.

8 J. P. Glatz, P. Soucek and R. Malmbeck, Reprocessing and Recycling of Spent Nuclear Fuel, 2015.

9 S. Trumm, A. Geist, P. J. Panak and T. Fanghaenel, Solvent Extr. Ion Exch., 2011, 29, 213-229.

10 D. Magnusson, B. Christiansen, M. R. S. Foreman, A. Geist, J.P. Glatz, R. Malmbeck, G. Modolo, D. Serrano-Purroy and C. Sorel, Solvent Extr. Ion Exch., 2009, 27, 97-106.

11 F. W. Lewis, L. M. Harwood, M. J. Hudson, M. G. B. Drew, J. F. Desreux, G. Vidick, N. Bouslimani, G. Modolo, A. Wilden, M. Sypula, T. H. Vu and J. P. Simonin, J. Am. Chem. Soc., 2011, 133 13093-13102.

12 A. Afsar, L. M. Harwood, M. J. Hudson, J. Westwood and A. Geist, Chem. Commun., 2015, 51, 5860-5863.

13 A. C. Edwards, C. Wagner, A. Geist, N. A. Burton, C. A. Sharrad, R. W. Adams, R. G. Pritchard, P. J. Panak, R. C. Whitehead and L. M. Harwood, Dalt. Trans., 2016 14 P. J. Panak and A. Geist, Chem. Rev., 2013, 113, 1199-1236. 15 A. Geist, U. Müllich, D. Magnusson, P. Kaden, G. Modolo, A Wilden and T. Zevaco, Solvent Extr. Ion Exch., 2012, 30, 433-444. 16 C. Wagner, U. Müllich, A. Geist and P. J. Panak, Solvent Extr. Ion Exch., 2015, 6299, 1-11.

17 C. Hill, in Advanced Separation Techniques for Nuclear Fuel Reprocessing and Radioactive Waste Treatment, 2011, pp. 311362.

18 P. Kaufholz, F. Sadowski, A. Wilden, G. Modolo, F. W. Lewis, A. W. Smith and L. M. Harwood, Nukleonika, 2015, 60, 815-820. 19 P. Kaufholz, G. Modolo, A. Wilden, F. Sadowski, D. Bosbach, C. Wagner, A. Geist, P. J. Panak, F. W. Lewis and L. M. Harwood, Solvent Extr. Ion Exch., 2016, 34, 126-140.

20 E. Macerata, E. Mossini, S. Scaravaggi, M. Mariani, A. Mele, W. Panzeri, N. Boubals, L. Berthon, M. C. Charbonnel, F. Sansone, A. Arduini and A. Casnati, J. Am. Chem. Soc., 2016, 138, 7232-7235

21 M. C. Nielsen, A. F. Larsen, F. H. Abdikadir and T. Ulven, Eur. J. Med. Chem., 2014, 72, 119-126.

22 D. M. Whittaker, T. L. Griffiths, M. Helliwell, A. N. Swinburne, L. S. Natrajan, F. W. Lewis, L. M. Harwood, S. A. Parry and C. A. Sharrad, Inorg. Chem., 2013, 52, 3429-3444.

23 M. Steppert, I. Císařová, T. Fanghänel, A. Geist, P. LindqvistReis, P. Panak, P. Štěpnička, S. Trumm and C. Walther, Inorg. Chem., 2012, 51, 591-600.

24 D. Lundberg, I. Persson and C. Ekberg, Dalt. Trans., 2013, 42 3767-3770.

25 R. Zong, G. Zhang, S. V. Eliseeva, J. C. G. Bünzli and R. P. Thummel, Inorg. Chem., 2010, 49, 4657-4664.

26 E. S. Andreiadis, R. Demadrille, D. Imbert, J. Pecaut and M Mazzanti, Chem. - A Eur. J., 2009, 15, 9458-9476.

27 A. L. Spek, Acta Crystallogr., 2015, 71, 9-18.

28 N. J. Williams, J. Dehaudt, V. S. Bryantsev, H. Luo, C. W.

Abney and S. Dai, Chem. Commun., 2017, in press.

29 P. Gans, A. Sabatini and A. Vacca, Talanta, 1996, 43, 17391753.

30 A. Bremer, D. M. Whittaker, C. A. Sharrad, A. Geist and P. J.

Panak, Dalt. Trans., 2014, 43, 2684-2694.

31 K. Binnemans, Coord. Chem. Rev., 2015, 295, 1-45. 